\title{
Research
}

\section{Developing Indicators for Monitoring and Evaluating Joint Management Effectiveness in Protected Areas in the Northern Territory, Australia}

\author{
$\underline{\text { Arturo Izurieta }}^{1}$, Bevlyne Sithole ${ }^{1}$, Natasha Stacey ${ }^{1}$, Hmalan Hunter-Xenie ${ }^{1}$, Bruce Campbell ${ }^{1}$, \\ Paul Donohoe $^{2}$, Jessie Brown ${ }^{3}$, and Lincoln Wilson ${ }^{4}$
}

\begin{abstract}
Joint management of protected areas is promoted in many countries around the world. It is considered a means to provide local communities, including indigenous people, with recognition of their cultural practices in the use and management of the natural resources within a protected area, while working together with governments to achieve conservation goals. However, implementation of effective joint management has often been difficult because capacities and expectations among partners differ. Here we explore the potential of using a participatory monitoring and evaluation approach as a means of not only agreeing among partners on the objectives of joint management but also of measuring progress toward those objectives. In particular, we first describe the process used to develop criteria and indicators for measuring joint management effectiveness of a protected area in the Northern Territory, Australia, involving the park's Aboriginal Traditional Owners, their legal representatives, government, and researchers. We then analyze the process of applying a participatory approach to developing indicators and its contribution to improving equity among the partners. We consider the effectiveness of a participatory process within the context of the relationships, capacities, skills, communication, and cross-cultural information sharing. We found that at the early stages of joint management, the partners mostly identify process indicators related to human and social capital assets. Cross-cultural engagement in the early stages of the monitoring and evaluation cycle is challenged by issues relating to communication, institutional and community capacities, representation, and flexibility in ways of working together while learning by doing. We conclude, however, that a participatory monitoring and evaluation approach in which partners agree equally on the identification of criteria and indicators to measure agreed management outcomes has the potential of improving equitable participation, decision making and working relationships, which in turn will lead to improved park management effectiveness and community outcomes.
\end{abstract}

Key Words: adaptive management, evaluation, indigenous people, joint management, management effectiveness, monitoring, participation, partnership, protected areas

\section{INTRODUCTION}

Joint management (sometimes referred to as comanagement, participatory management, or collaborative management) between state authorities and local people is a relatively well-recognized management approach to reconcile cultural and biodiversity conservation in protected areas (White et al. 1994, Davies et al. 1999, Lawrence 2000, Smyth 2001, Carlson and Berkes 2005, DeKoninck 2005, Plummer and Arai 2005, Berkes 2009). Borrini-Feyerabend et al. (2007:69) define joint management as "a partnership by which two or more relevant social actors collectively negotiate, agree upon, guarantee and implement a fair share of management functions, benefits and responsibilities for a particular territory, area or set of natural resources". Underlying this is the moral argument that conservation goals should contribute to, rather than conflict with, basic human needs (Mahanty et al. 2007).

Considerable attention has been given to the role of local and traditional knowledge in conservation (Berkes and Turner 2005, Ross et al. 2009) and yet indigenous people are still struggling to find a role 
in protected area (PA) decision making processes and management actions (Jaireth and Smyth 2003) and to effectively manage their land together with park management agencies. Joint management between Government agencies and Aboriginal Traditional Owners can be seen from two different cultural perspectives: the western and the indigenous perspective. Traditional Owners are defined as "local descent group of Aboriginals who have common spiritual affiliations to a site on the land...and are entitled by Aboriginal tradition to forage as of right over that land" (Aboriginal Land Rights Northern Territory Act 1976, Australia: Part 1, Section 3).

From the Aboriginal perspective, joint management is a process associated with community development in which the aim of control over their traditional lands is mainly driven by the need for a stronger cultural identity and self-determination, while from the government perspective, joint management is primarily a means to achieve conservation goals (Lawrence 2000). Rarely, however, have shared objectives within these different perspectives been identified and agreed by the partners or been followed by an assessment of their achievement.

Evaluation of management effectiveness of protected areas has been encouraged by different international fora, such as the World Parks Congress in 1992 and 2003, and the Convention on Biological Diversity Conference of the Parties of 2004, and most contemporary natural resource management programs or projects require inbuilt monitoring and evaluation (M\&E) to provide greater accountability, adaptive management, and social learning (Mahanty et al. 2007). There is a fast growing, burgeoning literature on the positive contribution made by collaborative or participatory monitoring and evaluation (PME) for natural resource management systems. In these examples concepts and approaches of comanagement (collaboration) and adaptive management (learning by doing) have been merged and applied to assist managers and communities to deal with, and learn from, complex ecological and social management systems (Armitage 2003, Olsson et al. 2004, Berkes 2009). This literature has included specific habitats such as forests (Fernandez-Gimenez et al. 2008, Setty et al. 2008); governance dimensions of comanagement (Cundill and Fabricius 2010); and tourism in PAs (Plummer and Fennell 2009), demonstrating contributions in partner capacity development, knowledge sharing through learning by doing, and trust building between stakeholders as part of a social learning process (Berkes 2009).

However, most protected area assessment tools focus on biodiversity outcomes achieved by government managed protected areas while recommending participation of local stakeholders in the assessment (Hockings et al. 2006). These tools provide little guidance on how to assess comanagement when partners share management authority and have different cultural backgrounds (Cundill and Fabricius 2009). Monitoring and evaluation of environmental management, including protected areas, thus tends to be narrowly focused on what the management wants to achieve (outcomes) rather than how the management arrangements work (Bellamy et al. 2001) and whether the institutional arrangements themselves are functioning effectively (processes) (George et al. 2004, Ross et al. 2004, Plummer and Armitage 2007). For instance joint management is a responsibility shared between Aboriginal Traditional Owners and government agencies for achieving both environmental, and social and cultural outcomes (Northern Territory Parks and Wildlife Conservation Act 2005, Australia) covering all aspects of protected area management from governance to on-the-ground, day-to-day activities. To achieve this requires good working relationships among the partners and consideration of crosscultural communication processes for making decisions together (Robinson et al. 2006). It follows that monitoring and evaluating jointly managed protected areas should assess not only the biophysical outcomes but the social, cultural and economic outcomes as well as the partnership arrangements and processes linked to the interests and rights of the partners (Bauman and Smyth 2007). Furthermore, the majority of evaluation frameworks for adaptive comanagement do not provide practical assistance about how to implement them in a collaborative way (Cundill and Fabricius 2009).

\section{Participatory monitoring and evaluation and joint management}

In principle, joint management embraces concepts of equitable participation, decision making and working together. This implies that not only would the management be participatory but so too should the monitoring and evaluation. Participatory 
monitoring and evaluation (PME) has been tried, in various forms, in many circumstances outside Australia (Abbot and Guijt 1998, Campbell et al. 2001, Campbell and Shackleton 2001, Moller et al. 2004, Mahanty et al. 2007, Evans and Guariguata 2008, Cundill and Fabricius 2010) but has received limited attention in Australian indigenous contexts (Davies et al. 1999) or with regard to jointly managed protected areas (George et al. 2004, Ross et al. 2004) in which indigenous people and government agencies share equal responsibilities for the protection and conservation of national parks and nature reserves. The principle of PME is that it can be used to empower local communities to analyze their own problems (Pretty and Vodouhe 1997, Estrella et al. 2001, Zukoski and Luluquisen 2002, Elwood 2006) by defining indicators, collecting indicator data, and analyzing the emerging data through learning by doing (Estrella et al. 2001, Fernandez-Gimenez et al. 2008). Both $\mathrm{PME}$ and joint management require that key stakeholders are included effectively in the monitoring and evaluation process (O'Sullivan 2004, Timko and Satterfield 2008) and that the powerful (in this case the park managers) are willing to incorporate the powerless (in this case the indigenous people) into the evaluation process (Guba and Lincoln 1989, Mathie and Greene 1997, Estrella et al. 2001, Fetterman 2001).

Monitoring and evaluation generally use a set of criteria and indicators to measure performance in natural resource systems. In this study we define monitoring as checking things you or someone else does over time by collecting information regularly about indicators on how things are going. The results help to measure changes and progress toward objectives or outcomes; evaluation is defined as learning, analyzing and discussing what has happened during a period of time, and how these lessons can help to improve actions for a similar period in the future (Mahanty et al. 2007).

Natural resource management monitoring programs have been criticized as being too quantitative, with too many indicators, thus becoming unworkable (Mahanty et al. 2007). Questions have been raised about whether PME is too soft, too qualitative, and too process oriented (Freedman 1998). But such qualitative and participatory approaches to monitoring and evaluation are often the only means available for assessing the quality of partnerships and relationships between stakeholders, capacities to carry out management, and satisfaction with social and cultural outcomes (Guijt 2007, Mahanty et al. 2007, Sayer et al. 2007, Setty et al. 2008). Applying a PME approach for joint management thus faces a tension between selecting and measuring criteria and indicators of biological outcomes from management, and more communitybased qualitative indicators of cultural and social achievements. A key factor for community-based indicators has been ease of use and their capacity to influence management (Reed et al. 2008). Use of participatory methodologies helps communities to develop indicators that are meaningful to them and can be implemented in an adaptive learning process (Ritchie et al. 2000, Reed et al. 2005, Reed et al. 2008). In the case of joint management, development of indicators by both the members of the community (Aboriginal Traditional Owners) and staff from the management agency makes it less likely that the monitoring system will be left out of the decision making process (Garcia and Lescuyer 2008).

Participatory monitoring and evaluation democratizes and enriches the assessment of a program (Freedman 1998, Jackson and Kassam 1998), providing equal opportunities for Aboriginal Traditional Owners (bottom-up approach) and government agencies (top-down approach) to agree on indicators that can satisfy both partners. Leaving the monitoring system to local communities has proven to be unsuccessful (Garcia and Lescuyer 2008) and capacities and skills often need to be transferred if the partners involved in joint management are to be sufficiently prepared and skilled to participate effectively (Guba and Lincoln 1989). However, a simple transfer from one partner to the other can emphasize the power disparity, necessitating support from outside sources and an independent facilitator (Evans and Guariguata 2008).

Issues related to the willingness of participants to take part in evaluations are important considerations as well. The willingness of stakeholders to participate in evaluation processes or express disagreements could be affected by fear of retaliation from those within the program who possess legal and/or institutional authority, especially when dealing with programs that are politically sensitive (Mathie and Greene 1997). Other stakeholders might be unwilling even to acknowledge another party's legitimate role or to make agreements with them (O'Faircheallaigh 2002). In Australia the willingness of Aboriginal 
people to participate in planning has been diminished by decades of denial of access to, and recognition of, traditional land and cultural rights (Smyth 2001).

The concept of participation has been put into practice in many natural resource management programs through the establishment of partnerships, especially cross-sectoral partnerships, connecting public, private, and other civil sectors (Eversole and Martin 2005, Swartling and Forrester 2010). We will describe the context of joint management in the Flora River Nature Park in the Northern Territory, Australia, which involves a partnership between the Northern Territory Parks and Wildlife Service and Wardaman Traditional Owners belonging to the country in which the park is situated.

The ultimate purpose was to assess the joint management effectiveness through the participatory development of criteria and indicators and thus establish a baseline for future evaluations. Although in this research we did establish a baseline, here we will focus on the participatory approach used in Flora River park, in particular, the methods and processes used to identify the criteria and indicators. We also describe the degree to which the participatory approach to develop the criteria and indicators with the partners affected the capacities and confidence of individuals and groups to participate in planning and in the formal decision making processes of joint management. We discuss the relevance of the indicators, the capacities of the partners to participate in joint management activities and the usefulness of a flexible "learning by doing" approach in cross-cultural situations.

\section{The Flora River (Giwining) Nature Park: Cultural, natural and joint management context}

Australia's experience of joint management began in the late 1970s in the Northern Territory (NT) as a mechanism to provide recognition of land rights to indigenous people while simultaneously providing a way to conserve the natural resources of that land in the national interest (Ross et al. 1994). Based on the 2005 Northern Territory Joint Management Agreement (currently in review as per July 2011) between the NT Government Parks and Wildlife Services (from now on Parks) and the Land Councils as legal representatives of traditional Aboriginal land owners, the Wardaman people and
Parks agreed on a planning process to develop a plan of management for Flora River Nature Park. The Northern Land Council (NLC) has a statutory responsibility and acts in relation to the aspirations of indigenous people in the northern part of the Northern Territory. The Parks and Wildlife Service is the state department with the responsibility for managing parks.

The plan is the result of various meetings on the park in which the partners agreed on the future directions to its day-to-day management, including the identification of management outcomes against which monitoring and evaluation could be carried out. The plan translates the aspirations of the Wardaman people to share with the public the cultural and natural significance of their traditional country. For Aboriginal people "country" refers to their ancestral lands for which they are responsible and phrases such as "on country" are used to refer to activities on such land.

The Northern Territory joint management initiative launched in 2005 identified, among other things, the importance of establishing a monitoring and evaluation framework whereby Parks and Wardaman Owners could determine the degree of progress in joint management actions in the park. The Flora River Nature Park was selected to test a participatory monitoring and evaluation approach, the results of which could later be replicated and applied at all 27 jointly managed parks in the NT.

The Flora River Nature Park (7,824 hectares) lies within the lands of the Wardaman people of the Victoria River District. The north and south-west portions of the Park are bordered by Wardaman Aboriginal land, owned by the Yubulyawun Aboriginal Land Trust and Djarrung Aboriginal Corporation. The Park is located $120 \mathrm{~km}$ south-west of Katherine (see Figure 1).

The park, which is named Giwining by Wardaman, contains many sites of significance to the Wardaman, particularly within the riverine area, and many of these have been registered under the Northern Territory Aboriginal Sacred Sites Act of 1989. Wardaman connection with the land comprises a complex set of traditional rights, benefits, obligations, and responsibilities. Wardaman people inherited this land from their ancestors and have the responsibility under their lore to care for their country. Stories and traditions, sacred sites and related "dreaming" (spiritual beliefs and associated 
Fig. 1. Location of Flora River Nature Park (source: Natural Resources, Environment, The Arts and Sports, Parks and Wildlife Commission 2011)

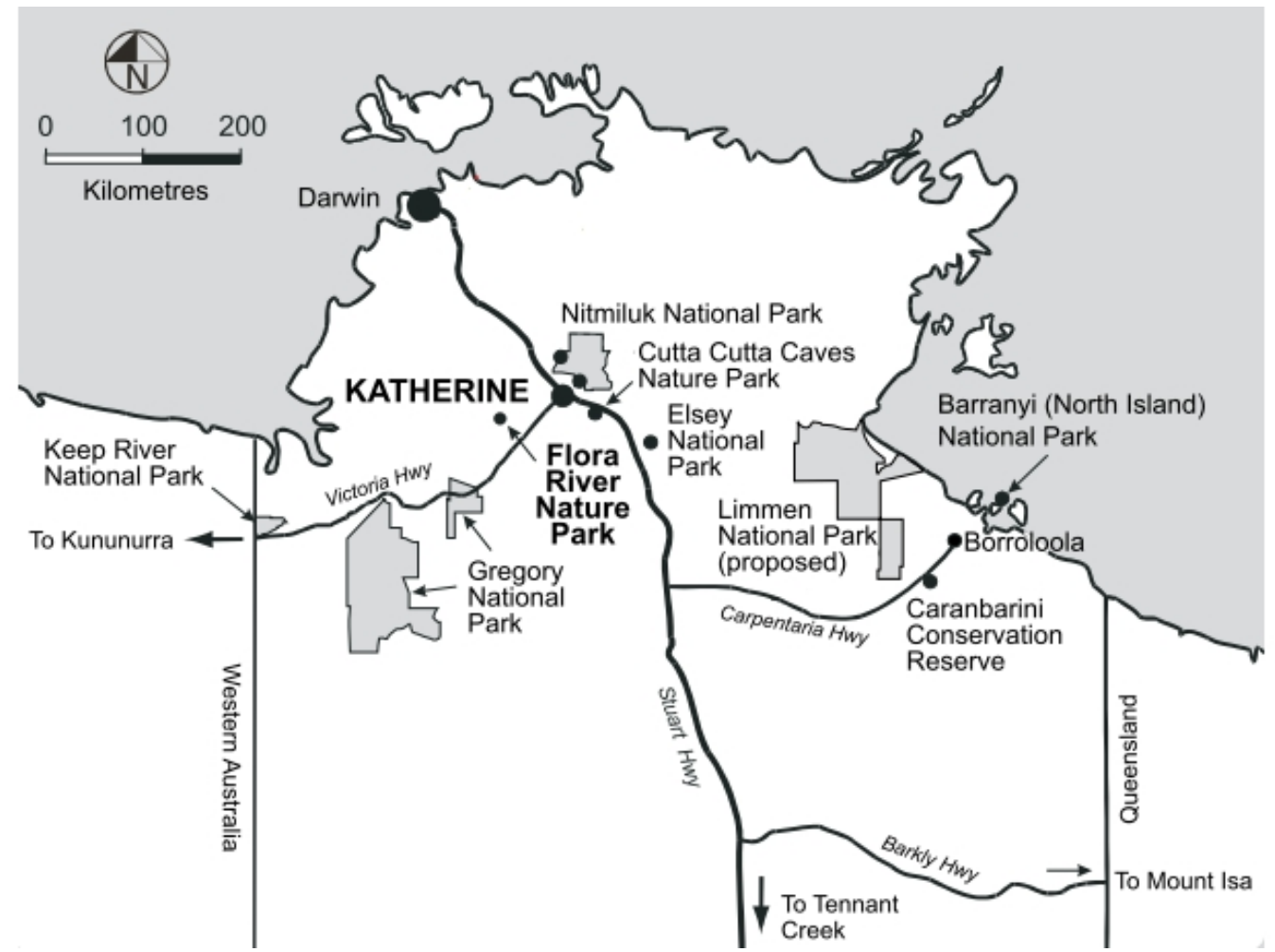

practices) are significant components of the Parks' cultural values, with each Wardaman clan inheriting its own particular country according to this tradition. This knowledge related to the management of the biophysical attributes of the park is of great interest and value to Parks and the wider community (Natural Resources, Environment, The Arts and Sport, draft Flora River Joint Management Plan July 2010, unpublished manuscript).

Settlement of the region mainly by British and other European migrants has had its impact on the structure of landholding groups and distribution of Wardaman people. Today, those Traditional Owners associated with the original clans come from a number of Wardaman families; its senior members continue to trace their connections to their traditional land (country). Some Wardaman live on their country near Flora River Nature Park in the communities of Djarrung and Mengenn; others live in the communities of Binjari and Kalano, outside of Katherine.
The park contains a diversity of savannah and associated habitats but the main feature has always been the Flora River and associated springs. It attracts around 1,200 visitors each year. Currently there are no tour operators within the park, but there are some opportunities for cultural and nature-based tour operations (Natural Resources, Environment, The Arts and Sport, draft Flora River Joint Management Plan July 2010, unpublished manuscript).

The park is jointly managed with the Parks district office in Katherine which has approximately 12 staff, including administration. This office has two Wardaman rangers contracted part-time to work at the Park, an arrangement requested by the Wardaman rangers themselves. Other Aboriginal people, particularly Wardaman, are hired under short term contracts to carry out specific works to assist the management of the park. These short term contracts are part of Parks' flexible employment program which aims to encourage Aboriginal 
people to assist in managing the parks and also provide opportunities for them to gain experience and skills in different park management activities.

\section{METHODS}

We used Participatory Action Research (PAR) (Greenwood et al. 1993, Kemmis and McTaggart 2005) to procure the equitable contribution of all partners in the development and application of indicators and to generate positive changes through the research (Coghlan and Brannick 2005). The research brought together concepts of management effectiveness of protected areas (Hockings et al. 2006) managed jointly in a cross-cultural environment, using a participatory monitoring and evaluation (PME) approach as a tool to strengthen the partnership (Sayer et al. 2007), and adapting to changes while co-learning by co-doing (Ross et al. 2004). All phases of the project required facilitated participation followed by a validation of all outputs and outcomes.

The phases and methods used to develop the indicators and the participatory monitoring and evaluation framework used in this project are shown in Figure 2. We focus here on the preparation phase, and anticipate reporting on research results from the outcomes of the application of the monitoring and evaluation framework to other parks in the Northern Territory at a later date. We held a series of meetings with partners to agree on the participatory approach, the joint management outcomes, criteria, and indicators to be monitored and later, training of partners to carry out the baseline assessment. These activities were conducted during 2007-2008 as part of the development of the Flora River park plan of management. There were three types of multipartner meetings held: more formal officebased meetings between partners and their representatives (e.g. Parks, Land Council on behalf of Wardaman Owners, and Charles Darwin University-CDU); facilitated workshops either in an office-based setting, and/or in more informal open-air surroundings at the Flora River park, the latter usually involving greater numbers of people from all partner groups.

Standard participatory methods, such as small focus groups and in some cases separate stakeholder groups, with an emphasis on oral and visual tools to aid discussions, were used to engage all partners. At the larger meetings since there were Aboriginal people present with limited English, where possible, discussions were held in both English and the local language, with Aboriginal participants translating for each other. These meetings also tended to involve Aboriginal men, women, and children. Field researchers (facilitators) and staff from the Northern Land Council, including an anthropologist assisting with Aboriginal engagement at some meetings, were experienced in Wardaman cultural practices and protocols. The selection of representatives of the Wardaman was determined by the Land Council staff who were also largely responsible for providing transport, meals, and daily fee payments to Traditional owners to participate in meetings and workshops. For the Wardaman, premeeting sessions were conducted by the Land Council officer to clarify the content to be discussed.

Observations by researchers on the relationships, empowerment, capacities, skills, communication, and information sharing processes among partners were recorded during the research. The Charles Darwin University (CDU) authors of this paper were contracted by the partners as facilitators to develop a participatory monitoring and evaluation process and undertake the activities described in the preparation phase (Figure 2). Their role involved applying principles and methods of participatory action research in the identification of indicators, and enabling the participation of partners in the process, provision of advice, information on best practices and approaches in protected area management, recording the information produced and communicating this to all partners for validation. Under the Joint Management agreement in the NT, the partners are required to implement a ME process in all parks and are employed to support joint management activities.

Two frameworks were used to classify the agreed criteria and indicators: the World Commission on Protected Areas management effectiveness framework (Hockings et al. 2006) in which indicators are classified according to six different elements of the protected area management cycle (context, planning, inputs, process, outputs, and outcomes); and the capital assets framework which assesses trends in five so-called capital assets: natural capital (biodiversity, ecosystem services), human capital (health, education, skills), social capital (institutional arrangements), physical capital (infrastructure and built assets), and financial capital (money and funds available) (Sayer et al. 2007). 
Fig. 2. Participatory monitoring and evaluation process (adapted from Hockings et al. 2006)

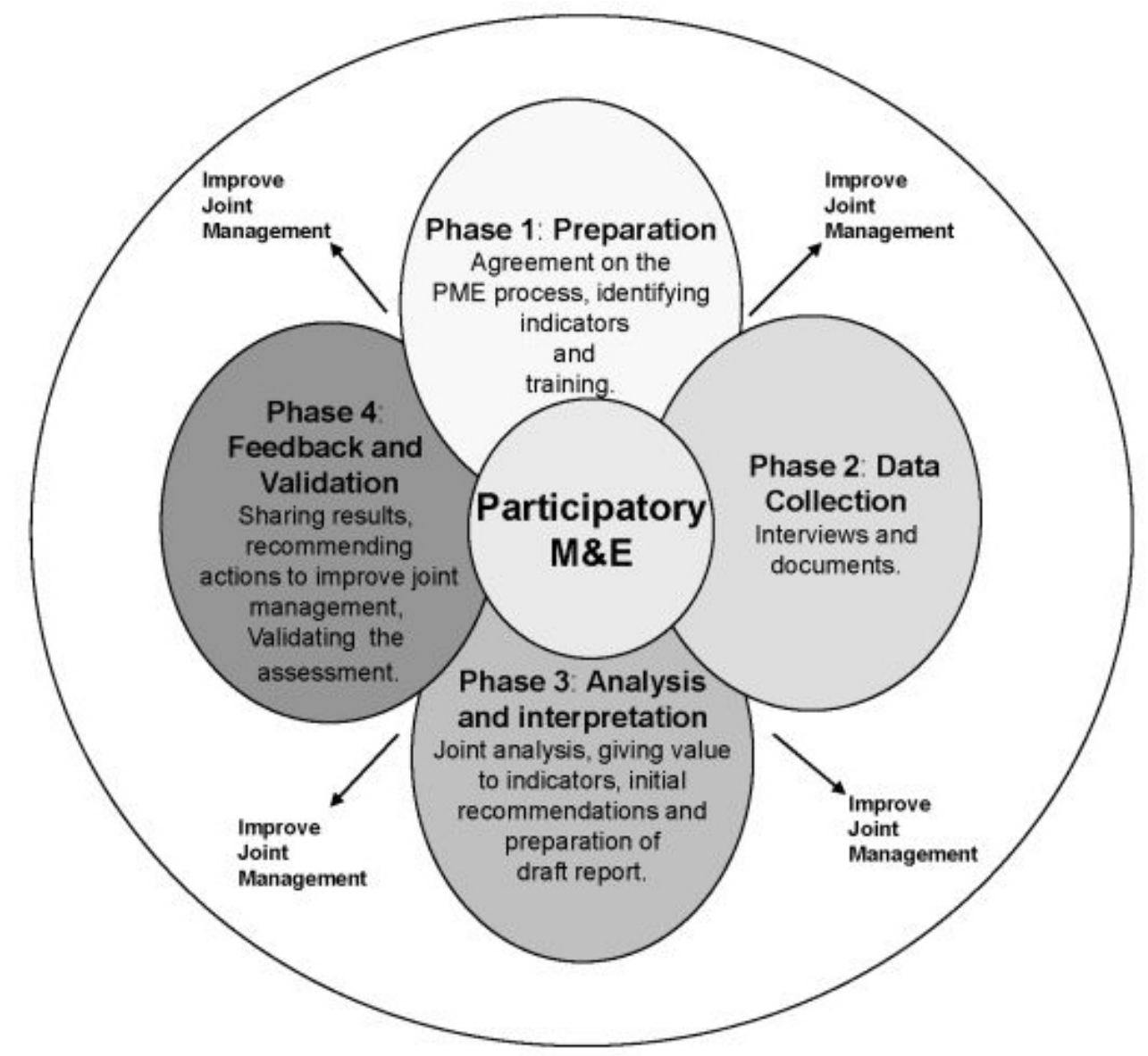

\section{RESULTS}

\section{Proposed joint management outcomes, criteria, and indicators}

Over a period of 11 months from May 2007 to April 2008, five drafts of the joint management outcomes, criteria, and indicators for Flora River were developed. A final version, which incorporated outcomes, criteria, indicators and means of verification, data collection, and responsibility, was agreed upon by partners after a joint review conducted with all partners at Flora River park. At the first meeting held at Flora River, five outcomes of joint management and roughly 50 indicators were suggested. The partners reviewed the list and on that basis the number of indicators was reduced. The expectations of Parks, the Northern Land Council and Wardaman for the criteria and indicators were varied. The concern that the list of indicators was too long dominated most discussions among the partners. While Parks wanted a smaller and more focused list and were concerned with the costs related to conducting a more comprehensive monitoring process, the Northern Land Council was more concerned with making sure that issues of concern to Traditional Owners in such arrangements were captured. Traditional Owners were satisfied with the coverage of the criteria and indicators where key concerns were addressed by some of the indicators in language they understood. The facilitators were careful that the criteria and indicators for measuring joint management performance reflected the concerns of all partners.

Consequently, partners were faced with the need to be responsive to partner concerns while at the same time being aware of the need for rigor and cost 
effectiveness in the process. The purpose and focus of the second joint partner meeting held at Flora River park was to ensure that all partners were familiar with the criteria and indicators and had the opportunity to comment on the final list. At this meeting, the number of indicators was reduced to 29. The indicators were grouped under five agreed joint management outcomes for Flora River park, namely:

- Joint management keeps Wardaman culture strong

- Real benefits accrue to the Wardaman from joint management

- Good dreaming among partners involved in joint management

- Good park management

- Effective participation by Wardaman in decision making in the park.

We recognize that participatory monitoring and evaluation requires longer periods for consultation; the identification of criteria and indicators was largely completed over two meetings at the Flora River park lasting two to three days but refinement and finalization of the criteria and indicators took much longer, with minor modifications to the indicators continuing up to the validation phase (Figure 2: Phase 4). One of the key challenges was that some of the indicators were very similar across the different outcomes. Agreement was reached among the partners during the training workshop (phase 1) to modify and remove two indicators and adjust the wording of one criterion to avoid what might seem like repetition of another indicator. The final list of 27 indicators associated with twelve criteria (Table 1) was later approved by the partners in mid 2009 (Figure 2: Phase 4).

The criteria and indicators identified in this participatory process covered various dimensions of management effectiveness of protected areas, including the biophysical, cultural, governance, socioeconomic, operational, and recreational (Leverington and Hockings 2004) with an emphasis on indicators that assess processes such as the communication between the partners, two-way learning, involvement in decision making, planning and budgeting, and facilitation of joint management meetings. Other indicators were related to the context (respect of cultural sites and access to country), planning (annual business plans), inputs (infrastructure and equipment, staff, funding), outputs (signage and general information on cultural and natural values of the park, records or data on traditional ecological knowledge applied to the park), and outcomes (state of the park in terms of execution of plans and satisfaction of the partners, and Wardaman people being employed, trained and provided with business opportunities in the park).

When the 27 agreed indicators were classified according to the framework for assessing management effectiveness of protected areas (Hockings et al. 2006), almost half were categorized as process indicators assessing four of the five joint management outcomes identified for Flora River (Table 2).

There was a similar bias in indicator distribution when they are classified against a capitals framework (Sayer et al. 2007) with more than half representing changes in social and human capital and only one each assessing changes in natural or physical capital (Table 3).

\section{Participation of the partners}

The involvement of the partners in the preparation phase of the participatory monitoring and evaluation process, particularly the identification of criteria and indicators, was carried out in conjunction with the planning process to develop the Flora River plan of management. The number and representation of Wardaman people varied at the planning sessions, with the exception of some regular participants. Thus, while we had consistently high participation and presence at the meetings, some individuals played a major role. Participation was dominated by older people who tended to know the Park and generally women spoke up more than men. However, we observed that these individuals tended to have authority in the community and were formally or informally assigned as spokespersons in the meetings. Passive participation during the meetings was characteristic of Aboriginal communities and accepted as a result of the fact that while most people are concerned to know what is happening on their lands, only particular individuals are able to make decisions regarding that land. In addition, meetings held in the Park usually resulted in increased attendance and greater cultural acceptability by Wardaman. 
Table 1. Joint management monitoring and evaluation criteria and indicators for Flora River Nature Park

Joint management outcomes and criteria Indicators

Outcome 1. Joint management keeps Wardaman culture strong

1.1 Participation and attendance of Wardaman at 1.1 .1 Number of on country meetings held each year on country meetings $\dagger$

1.1.2 Level of Indigenous involvement in on country meetings

1.1.3 Satisfaction gained from attending on country meetings

1.2 Successful management of the park based on 1.2.1 Parks staff demonstrate high level of cultural awareness two- way learning $\ddagger$

\subsubsection{Positive attitudes toward western knowledge among the Wardaman}

1.2.3 Good examples of two-way learning in the way the park is managed

1.3 High level of satisfaction among Traditional Owners about the protection of significant

1.3.1 Satisfaction among Traditional Owners about adherence to conditions for access cultural sites§ to cultural sites and their protection.

Outcome 2: Real benefits accrue to the Wardaman from joint management

2.1 Wardaman get employment from the joint management arrangements.

2.2 Contracts and projects are undertaken by the Wardaman

2.3 Feasibility for enterprise in the park is assessed and discussed
2.1.1 Level of employment of Traditional Owners in meaningful jobs in the park

2.1.2 Satisfaction among Wardaman about the employment benefits associated with joint management

2.2.1 Percentage allocation in the budget for Traditional Owner employment, projects and contracts

2.2.2 Level of satisfaction of both partners regarding the delivery of service contracts in the park

2.3.1 Satisfaction with outcomes of feasibility studies/assessments for enterprises in the park

Outcome 3: Good dreaming among partners involved in joint management|

3.1 Good dreaming among partners involved in joint management

3.2 Good communications among partners over joint management
3.1.1 Wardaman are satisfied with joint management relationship and processes

3.2.1 Good involvement in, and understanding of, planning procedures and money story among the Wardaman

3.2.2 Wardaman are satisfied with the amount of knowledge they hold on key aspects of park management.

3.2.3 Wardaman satisfied that their concerns are addressed during planning processes.

3.2.4 Cultural information about the park is readily available 
Outcome 4: Good park management

4.1 Good management of the park so that country 4.1.1 Good biodiversity outcomes from the operational plan on fire, weeds, and feral is healthy II animals

4.1.2 Good partnerships with other key stakeholders in the park, i.e., stakeholders other than Parks and Wardaman.

4.2 Strong Tourism

4.2.1 Visitors to the park are satisfied with the park.

4.2.2 Infrastructure in the park and around the camps and other areas is well maintained.

4.2.3 Partners are satisfied that messages and images of the park are consistent with the Park's values

Outcome 5: Effective participation by Wardaman in decision making in the park

5.1 Effective participation by Wardaman in decision making in the park
5.1.1 Good attendance and participation in meetings at Parks Katherine office by Wardaman

5.1.2 Good relations between Wardaman and Parks officials

5.1.3 Clarity of roles and responsibilities among all stakeholders

5.1.4 Strong and effective joint management committee

5.2.1 Good facilitation in the meetings

5.2 Level of effectiveness in conducting meetings

†On country" refers to Aboriginal ancestral lands for which they are responsible, in this case Flora River park and phrases such as "on country" are used to refer to activities in the park.

\$Wo-way learning refers to the sharing and application of both Indigenous and western knowledge in park management.

§Aboriginal Traditional Owners and Wardaman of Flora River park are used interchangeably.

Good dreaming refers to good relationships between the partners involved in protecting the park

THealthy country refers to the good condition of all aspects of the park, including sacred sites.

One of the main limitations of participation was the level of numeracy and literacy among the Wardaman. Ensuring that everyone understood took more time and often older people were exhausted and children were restless from longer discussion sessions. The death of Wardaman, in particular elders who have major responsibilities for decision making, had an impact on the activities carried out by the partners. Flexibility by Parks and NLC staff to accommodate Wardaman cultural practices into activities was observed during this research. For example, meetings were sometimes postponed at short notice to accommodate cultural needs and the hiring of two Wardaman rangers on a part-time basis was arranged by Parks in a way that respected their different duties and responsibilities as Traditional Owners.

Overall, relationships between all Wardaman, including children, and all Park rangers were relatively friendly, particularly outside meeting times at the Park, when both partners shared a walk to the river to fish. These informal opportunities during meetings and workshops were important in strengthening the personal and working relationships among the partners. The number and representation of Parks staff were relatively constant throughout the preparation phase activities. The Parks staff 
Table 2. Classification of joint management indicators for Flora River Nature Park based on the World Commission on Protected Areas framework for assessing management effectiveness of protected areas (Hockings et al. 2006)

\begin{tabular}{|c|c|c|c|c|c|c|}
\hline \multirow[b]{2}{*}{ Joint management outcomes } & \multicolumn{6}{|c|}{ Number of indicators by management effectiveness category } \\
\hline & Context & Planning & Input & Process & Output & Outcome \\
\hline $\begin{array}{l}\text { Outcome } 1 \text {. Joint management keeps } \\
\text { Wardaman culture strong }\end{array}$ & 1 & & & 5 & 1 & \\
\hline $\begin{array}{l}\text { Outcome } 2 \text { : Real benefits accrue to the } \\
\text { Wardaman from joint management }\end{array}$ & & & 1 & & 3 & 1 \\
\hline $\begin{array}{l}\text { Outcome 3: Good dreaming among partners } \\
\text { involved in joint management }\end{array}$ & & 1 & 1 & 3 & & \\
\hline Outcome 4: Good park management & & & 1 & 1 & & 3 \\
\hline $\begin{array}{l}\text { Outcome 5: Effective participation by } \\
\text { Wardaman in decision making in the park }\end{array}$ & & & & 4 & 1 & \\
\hline Total number of indicators & 1 & 1 & 3 & 13 & 5 & 4 \\
\hline
\end{tabular}

complement in Katherine has been stable in the last four to five years, with any staff turnover having little impact on the management of Flora River and the relationship with the Wardaman. Participation of Northern Land Council staff was higher during the earlier planning sessions, ending with just one staff accompanying the last meeting and the subsequent monitoring activities during later phases of the project.

\section{DISCUSSION}

\section{Types and number of indicators}

Protected area management, regardless of its regime, whether it be government, private, joint, or community-based, seeks to achieve its goals through effective management. In the joint management of Flora River Nature Park, two culturally different partners share the responsibility of managing the park.

The indicators identified through participatory processes and their application to joint management of Flora River showed that management process indicators were much more numerous than other types of management indicators, with a particular emphasis on indicators assessing changes in social capital over other forms of indicators. These management process indicators are consistent with Plummer and Armitage's (2007) core components of adaptive comanagement, which assign greater importance to social capital or process indicators. The processes that Parks and the Wardaman agreed on to assess related primarily to the way they hope to communicate with each other, how they intend to work together in decision making, and how they wish to learn from each other. On the one hand, the type of indicators agreed by the partners reflect their recognition that joint management involves the delivery not only of biophysical but also social outcomes and, on the other, reflects the need to work on communication and decision making processes that will make the cross-cultural partnership more equitable. This is particularly noticeable when both partners assess indicators and jointly recommend improvements to joint management. The result is a set of indicators that cover natural assets indicators and biophysical outcomes with social assets indicators and associated processes, which is more representative of the spectrum of management effectiveness.

How many criteria and indicators should there be? It has been suggested that stakeholders' interests 
Table 3. Classification of joint management indicators for Flora River Nature Park against a capital assets framework (Sayer et al. 2007)

\begin{tabular}{|c|c|c|c|c|c|}
\hline \multirow[b]{2}{*}{ Joint management outcomes } & \multicolumn{5}{|c|}{ Number of indicators by capital asset } \\
\hline & Financial & Human & Natural & Physical & Social \\
\hline $\begin{array}{l}\text { Outcome } 1 \text {. Joint management keeps Wardaman } \\
\text { culture strong }\end{array}$ & & 3 & & & 4 \\
\hline $\begin{array}{l}\text { Outcome 2: Real benefits accrue to the } \\
\text { Wardaman from joint management }\end{array}$ & 5 & & & & \\
\hline $\begin{array}{l}\text { Outcome 3: Good dreaming among partners } \\
\text { involved in joint management }\end{array}$ & & 2 & & 1 & 2 \\
\hline Outcome 4: Good park management & & & 1 & 2 & 2 \\
\hline $\begin{array}{l}\text { Outcome 5: Effective participation by } \\
\text { Wardaman in decision making in the park }\end{array}$ & & 1 & & & 4 \\
\hline Total number of indicators & 5 & 6 & 1 & 3 & 12 \\
\hline
\end{tabular}

define the number of indicators (Evans and Guariguata 2008); in assessing the performance of conservation and development interventions, others (Sayer et al. 2007) have recommended that partners identify four to six indicators for each capital asset, and five to six conservation indicators, acknowledging some overlap between natural capital and conservation indicators. Reed and collaborators (2005) proposed a set of 42 indicators to assess sustainability, grouping them into human, support, and natural subsystems, while Cundill and Fabricus (2009) do not identify an optimum number but instead highlight criteria for effective monitoring and evaluation whereby indicators must: (1) be integrative at spatial and temporal scales, (2) integrate both social and ecological variables, (3) measure social ecological resilience, and (4) monitor outcomes and processes. At Flora River partners identified 29 indicators under each of five key outcomes and later assessed 27 indicators. It is important to link the indicators to the visions and goals of the stakeholders to assure the partners' engagement in their development and implementation (Reed et al. 2005). For Flora River the visions and goals identified by the partners are reflected in the five agreed park management outcomes identified during the simultaneous development of the management plan, which are measured by the agreed sets of indicators identified.
The PME approach enabled the partners to identify indicators to measure how they are tracking against goals and, more importantly, management outcomes that they themselves identified. The partners acknowledged the trade-offs required to assess detailed dynamics of partner relationships and capacities, while implementing a participatory monitoring and evaluation process that is workable and manageable in terms of time, human capacity, and resources available.

\section{Achieving equitable participation of partners}

Joint management in the Northern Territory involves two different cultures working together, and thus, two different cultures understanding, applying, and corroborating on a monitoring protocol. Although we have shown that this is possible, we recognize participation varies between and among partners and can be influenced by various individual, social, cultural, historical, institutional, and logistical factors (Mannigel 2008). In this case, participation in developing the criteria and indicators was associated with the challenge of aligning with Parks' planning process to develop the Flora River management plan. In order to align with the management planning process, close working relationships and information sharing was required 
among the partners. In general, it was mostly the same people from the three partner organizations attending the meetings and workshops. In addition, individual, social, and cultural factors, such as the self-confidence of partners in participating in a new joint management process, absenteeism for cultural reasons, and logistical difficulties for participants to attend meetings must be recognized and considered. Nevertheless, the finalization by the partners of the criteria and indicators was completed and the baseline assessment results later validated (phase 4), giving strength to the whole monitoring and evaluation process, highlighting the applicability of indicators that are meaningful to the partners (Reed et al. 2008), particularly to the Wardaman people.

While all stakeholders in the process desired active involvement in various aspects of parks planning and management, there are many constraints and barriers to greater community engagement. One of the key concerns related to community involvement in monitoring and evaluation is the low level of literacy and numeracy, which limits the extent to which community members can genuinely participate in anything other than the verbal and visual aspects of the process. Observations on the willingness of Parks staff to participate in the process showed a satisfactory disposition to share knowledge, experience, and work with the Wardaman. This was obvious during all the meetings in the office or at the park. Monitoring joint management progress and achievements is new to the management of Flora River and, in general, to all parks in the Northern Territory, and as such, allocating time from the already limited Parks staff for the monitoring activities was challenging. These challenges can also be applied to the Northern Land Council, which has fewer staff assigned to joint management than does Parks, as the staff of the Northern Land Council are engaged in joint management activities at a number of other parks located hundreds of kilometers from their main offices. The level of engagement and capacities of the partners, including in terms of numeracy and literacy and knowledge of planning and evaluation processes and methods, described by Freedman (1998), have been tackled to some extent by adopting participatory methods to accommodate capacities, and by engaging the support of an external facilitator (Evans and Guariguata 2008).

The participatory process used to develop and later apply this monitoring and evaluation framework required a great deal of effort to organize the partners to carry out the different activities of the process. Limited staff and lack of experience in participatory monitoring and evaluation from Parks and Northern Land Council hampered the early stages of institutionalizing a participatory monitoring and evaluation process to assist joint management, as neither of the partners seemed prepared to undertake the process without facilitation and support from an external party, in this case, Charles Darwin University. The facilitation by the researchers in communication and information sharing (e.g., sharing of information among partners and coordination of meetings) and advice on participatory monitoring and evaluation approaches, and adaptive management for protected areas as part of the development and application of the monitoring and evaluation framework, played a key role in promoting a closer working relationship between the partners. It provided extra human capacity to support the process, which may not have been possible without the outside expert facilitation. By agreeing on criteria and indicators and the entire monitoring and evaluation process, the partners took initial steps toward establishing equitable opportunities to decide on what and how this should be achieved in a joint management situation, especially in relation to activities conducted in the park.

The issue of achieving equitable participation between the government agency (top-down approach with power) and the Aboriginal Traditional Owners (bottom-up approach with less power) is particularly challenging when the government agency possesses many more resources (human, financial, and physical assets) than their Aboriginal partners. However, the participatory process developed allowed for Parks staff and Traditional Owners to have equal opportunities to engage and participate in the development of criteria and indicators and later to jointly assess joint management through the provision of the same opportunities for contributions. This has provided a baseline from which the level of equity in representation and opportunities for input to planning and decision making and planning as part of an equitable partnership as envisaged by the 2005 Joint Management Agreement can be measured. This is consistent with examples elsewhere in which less powerful indigenous community members have demonstrated greater benefits when participating in monitoring community forestry arrangements (McDougall et al. 2007). 
The limitations and differences in the capacity of the partners to engage in new processes such as monitoring and evaluation, highlights the need to be flexible and able to adapt to decisions based on a "learning by doing" approach. In such processes where Parks is usually seen as the partner with more power, for example, in terms of financial, human resources, and infrastructure capacity, one could imagine that the agreed outcomes and indicators to assess these have a bias towards Parks' interests. This is where facilitation by the researchers played a key role in minimizing biases by enabling equal space for participation and contribution by both partners and by ensuring that all desired outcomes are included. In a joint management context, providing facilitation has allowed for the greater participation of Aboriginal people, which has given them greater power in decision making processes, providing greater confidence to communicate with partners, i.e., government agency representatives, to make decisions about the park.

\section{Participatory monitoring and evaluation process in establishing joint management indicators}

The participation of the Wardaman people in the development of the criteria and indicators was linked to the participatory planning process undertaken earlier to formulate the Flora River management plan. It is not known how the identification of criteria and indicators would have transpired had it been disconnected from the planning process. In order for the project to succeed, monitoring and evaluation will now need to be integrated into the management plan and or its implementation through the annual business planning activities and not treated as a separate function and responsibility (Woodhill 2000). In addition it will require the partners to incorporate dedicated monitoring and review sessions as part of regular joint management governance activities in order to review their progress in joint management effectiveness. The partners have understood what monitoring is for, and thus, have invested time and effort into its development and initial application. They have also felt monitoring and evaluation to be an instrument that can encourage their input in identifying outcomes and indicators themselves rather than through an external or top-down approach. This provides an opportunity for direct participation and thus improves equity in making decisions. In other words, participation in monitoring and evaluation is being seen as an end as well as a means (Diamond 2002), whereby participants feel there is an opportunity to have a say and have ownership of what joint management demands from them and what it can offer. The process was not seen simply as a way of obtaining or providing information during joint management, but rather as an opportunity for participants to learn from each other, by hearing and sharing each other's views and management desires and strive for improvement in their capacity to make joint management happen (Woodhill 2000). It was recognized that participatory monitoring increases the engagement of key stakeholders in the planning process, so that they are partners rather than subjects of the final evaluation (Zukoski and Luluquisen 2002).

\section{CONCLUSION}

Despite the questions and critiques over participatory approaches (Jackson and Kassam 1998), we concluded that participatory monitoring and evaluation made a valuable contribution to the first stages of a joint management partnership by providing a structured and agreed framework within which partners could talk and learn about improving how they work together. The agreed set of indicators reflect a common ground reached by the partners reflecting their own needs and areas of interest as well as agreement to work together in a partnership to jointly manage Flora River Nature Park. This is in contrast to previous experiences when Aboriginal people have had little say in management activities.

Our experiences at Flora River suggest that a PME approach which seeks to involve partners in the identification of management outcomes and indicators as well as their involvement in other stages of the process provides an opportunity to seek objectivity and ownership of participatory evaluation. Furthermore, it is evident that this process has led to equitable decision making which in turn will hopefully lead to improved management effectiveness and community outcomes. It is clear that the current capacities of the partners to carry out PME are not at an optimum level and the assistance of an external facilitator will be needed for some time if PME is to be an ongoing element of joint management arrangements in the Northern Territory.

We foresee future research on the dynamics of the application of indicators to assess joint management as it progresses over time. It would be pertinent to 
investigate how long the partners will have taken to strengthen their relationships through a series of evaluations on the processes and changes related to communications, sharing, and learning across diverse knowledge and management systems and making decisions and working together. Ultimately, it will lead us to understand how joint management contributes to improve social, cultural, and economic outcomes for indigenous people.

Responses to this article can be read online at:

http://www.ecologyandsociety.org/vol16/iss3/art9/responses/

\section{Acknowledgments:}

This research was conducted with financial support from The Australian Research Council (ARC), the Northern and Central Land Councils, the Northern Territory (NT) Department of Natural Resources, Environment, The Arts and Sport, and Charles Darwin University (CDU) as part of an Australian Research Council (ARC) Linkage project "Does monitoring and evaluation improve joint management? The case of national parks in the Northern Territory". This research would have not been possible without the support from the Wardaman people and all project partners. We acknowledge the assistance of Kristal Coe, Stephen Garnett and Dermot Smyth (CDU) who provided comments on earlier drafts.

\section{LITERATURE CITED}

Abbot, J., and I. Guijt. 1998. Changing views on change: participatory approaches to monitoring the environment. Discussion paper No.2. International Institute for Environment and Development, London, UK.

Armitage, D. 2003. Traditional ecological knowledge, adaptive management and the sociopolitics of conservation in Central Sulawesi, Indonesia. Environmental Conservation 39:79-90.

Bauman, T., and D. Smyth. 2007. Indigenous partnerships in protected area management in Australia: three case studies. Australian Institute of
Aboriginal \& Torres Strait Islander Studies, Canberra, Albert Park, Australia.

Bellamy, J. A., D. H. Walker, G. T. McDonald, and G. J. Syme. 2001. A systems approach to the evaluation of natural resource management initiatives. Journal of Environmental Management 63:407-423. http://dx.doi.org/10.1006/jema.2001.0493

Berkes, F. 2009. Evolution of co-management: role of knowledge generation, bridging organizations and social learning. Journal of Environmental Management 90:1692-1702.

Berkes, F., and N. Turner. 2005. Knowledge, learning and the resilience of social ecological systems. Pages 27-31 in L. Robson, editor. Managing the commons: conservation of biodiversity. Consejo Civil Mexicano para la Silvicultura Sostenible A.C., the Christiensen Fund, Ford Foundation, SEMARNAT, Instituto Nacional de Ecologia (INE), Mexico, D.F., Mexico.

Borrini-Feyerabend, G., M. Pimbert, M. Taghi Farvar, A. Kothari, and Y. Renard. 2007. Sharing Power: A Global Guide to Collaborative Management of Natural Resources. Earthscan, London, UK.

Campbell, B., J. A. Sayer, and P. Frost. 2001. Assessing the performance of natural resource systems. Conservation Ecology 5:22. http://dx.doi. org/10.1079/9780851997315.0267

Campbell, B., and M. Shackleton. 2001. The organizational structures for community-based natural resources management in southern Africa. African Studies Quarterly 5:87-114.

Carlson, L., and F. Berkes. 2005. Co-management: concepts and methodological implications. Journal of Environmental Management 75:65-76. http://dx. doi.org/10.1016/i.jenvman.2004.11.008

Coghlan, D., and T. Brannick. 2005. Doing action research in your own organization. Second edition. Sage Publications, Inc., New Delhi, India.

Cundill, G., and C. Fabricius. 2009. Monitoring in adaptive co-management: toward a learning based approach. Journal of Environmental Management 
90:3205-3211. http://dx.doi.org/10.1016/j.jenvman .2009 .05 .012

Cundill, G., and C. Fabricius. 2010. Monitoring the governance dimension of natural resource comanagement. Ecology and Society 15:15. [online] URL: http://www.ecologyandsociety.org/vol15/iss1/ $\underline{\operatorname{art} 15 /}$

Davies, J., K. Higginbottom, D. Noack, H. Ross, and E. Young. 1999. Sustaining Eden. Indigenous Community Wildlife Management in Australia. International Institute for Environment and Development (IIED) Evaluating Eden Series. IIED, London, UK.

DeKoninck, V. 2005. Joint management of Banteng (Bos javanicus) in a contested cultural landscape: observations and implications. Human Dimensions of Wildlife 10:123-135. http://dx.doi.org/10.1080/1 $\underline{0871200590931815}$

Diamond, N. 2002. Lessons from a 2000 World Bank e-discussion. Issue 1. World Bank-Global Environment Facility Program, Washington D.C., United States.

Elwood, S. 2006. Critical issues in participatory GIS: deconstructions, reconstructions, and new research directions. Transactions in GIS 10:693-708. http://dx.doi.org/10.1111/j.1467-9671.2006.01023. $\underline{\mathrm{x}}$

Estrella, M., J. Blauert, D. Campilan, J. Gavena, J. Gonsalves, I. Guijt, D. Johnson, and R. Ricafort, editors. 2001. Learning from change: issues and experiences in participatory monitoring and evaluation. International Development Research Centre, Ottawa, Canada.

Evans, K., and M. Guariguata. 2008. Participatory monitoring in tropical forest management: a review of tools, concepts and lessons learned. Center for International Forestry Research (CIFOR), Bogor, Indonesia.

Eversole, R., and J. Martin. 2005. Participation and governance in regional development. Pages 1-14 in R. Eversole, and J. Martin, editors. Participation and governance in regional development: global trends in an Australian context. Ashgate, Hampshire, UK.

Fernandez-Gimenez, M., H. Ballard, and V. Sturtevant. 2008. Adaptive management and social learning in collaborative and community-based monitoring: a study of five community-based forestry organizations in the western USA. Ecology and Society 13(2):4. [online] URL: http://www.eco logyandsociety.org/vol13/iss2/art4/

Fetterman, D. 2001. Foundations of empowerment evaluation. Evaluation and Program Planning 24:363-373. http://dx.doi.org/10.1016/S0149-7189 (01)00030-1

Freedman, J. 1998. Simplicities and Complexities of Participatory Evaluation. Pages 23-35 in E. T. Jackson, and Y. Kassam, editors. Knowledge shared: participatory evaluation in development cooperation. Kumarian, Ottawa, Canada.

Garcia, C., and G. Lescuyer. 2008. Monitoring, indicators and community based forest management in the tropics: pretexts or red herrings? Biodiversity and Conservation 17:1303-1317. http://dx.doi.org/ 10.1007/s10531-008-9347-y

George, M., J. Innes, and H. Ross. 2004. Managing sea country together: key issues for developing cooperative management for the GBRWHA. Technical Report No.50. CRC Reef Research Centre, Queensland, Australia.

Greenwood, D. J., W. F. Whyte, and I. Harkavy. 1993. Participatory action research as a process and as a goal. Human Relations 46:175-192. http://dx.d oi.org/10.1177/001872679304600203

Guba, E., and Y. Lincoln. 1989. Fourth generation evaluation. SAGE Publications, Newbury Park, London, UK.

Guijt, I., editor. 2007. Negotiated learning: collaborative monitoring in forest resources management and research. Resources For the Future, Washington, D.C., USA.

Hockings, M., S. Stolton, F. Leverington, N. Dudley, and J. Courrau. 2006. Evaluating effectiveness: a framework for assessing management effectiveness of protected areas. Second edition. IUCN, Gland, Switzerland. http://dx.doi.org/10.2305/ IUCN.CH.2006.PAG.14.en

Jackson, E. T., and Y. Kassam, editors. 1998. Knowledge shared: participatory evaluation in development cooperation. International Development Resarch Council/ Kumarian, West Hartford, Connecticut, USA. 
Jaireth, H., and D. Smyth, editors. 2003. Innovative governance: indigenous peoples, local communities and protected areas. Anne Books, New Delhi, Chennai, Kolkata, India.

Kemmis, S., and R. E. McTaggart. 2005. Participatory action research: communicative action and the public sphere. In N. K. Denzin, and Y. S. Lincoln, editors. The SAGE handbook of qualitative research. SAGE Publications, Thousand Oaks.

Lawrence, D. 2000. Kakadu: The making of a national park. The Miegunyah Press, Melbourne University Press, Melbourne, Australia.

Leverington, F., and M. Hockings. 2004. Managing in the face of global change: the role of evaluating management effectiveness. Pages 169-214 in C. V. Barber, K. R. Miller, and M. Boness, editors. Securing protected areas in the face of global change: issues and strategies. IUCN, Gland, Switzerland, Cambridge, UK.

Mahanty, S., N. Stacey, A. Holland, and S. Menzies. 2007. Learning to learn: designing monitoring plans in the Pacific Islands International Waters Project. Ocean and Coastal Management 50:392-410. http: //dx.doi.org/10.1016/j.ocecoaman.2006.09.004

Mannigel, E. 2008. Integrating parks and people: how does participation work in protected area management? Society and Natural Resources 21:498-511. http://dx.doi.org/10.1080/0894192070 $\underline{1618039}$

Mathie, A., and J. Greene. 1997. Stakeholder participation in evaluation: how important is diversity? Evaluation and Program Planning 20:279-285. http://dx.doi.org/10.1016/S0149-7189 (97)00006-2

McDougall, C., C. Khadka, and S. Dangol. 2007. Using monitoring as leverage for equal opportunity in Nepal. Pages 84-93 in I. Guijt, editor. Negotiated learning: collaborative monitoring in forest resource management. Resources for the Future, Washington, D.C, USA.

Moller, H., F. Berkes, P. Lyver, and M. Kislalioglu. 2004. Combining science and traditional ecological knowledge: monitoring populations for co- management. Ecology and Society 9(3):2. [online] URL: http://www.ecologyandsociety.org/vol9/iss3/ $\underline{\operatorname{art} 2 /}$

Natural Resources, Environment, The Arts and Sports, Parks and Wildlife Commission. Accessed 2011. Flora River Nature Park Fact Sheet. [online] URL: http:http://www.nt.gov.au/nreta/parks/find/pdf/ florariver.pdf

O'Faircheallaigh, C. 2002. A new approach to policy evaluation: mining and indigenous people. Ashgate Publishing Company, Aldershot, UK.

Olsson, P., C. Folke, and F. Berkes. 2004. Adaptive comanagement for building resilience in socialecological systems. Environmental Management 34:75-90. http://dx.doi.org/10.1007/s00267-003-0101-7

O'Sullivan, R. 2004. Practicing evaluation: a collaborative approach. SAGE Publications, Thousand Oaks, California, USA; London, UK; New Delhi, India.

Plummer, R., and S. Arai. 2005. Co-management of natural resources: opportunities for and barriers to working with citizen volunteers. Environmental Practice 7:221-234. http://dx.doi.org/10.1017/S146 $\underline{6046605050362}$

Plummer, R., and D. Armitage. 2007. A resiliencebased framework for evaluating adaptive comanagement: linking ecology, economics and society in a complex world. Ecological Economics 61:62-74. http://dx.doi.org/10.1016/j.ecolecon.2006 $\underline{.09 .025}$

Plummer, R., and D. Fennell. 2009. Managing protected areas for sustainable tourism: prospects for adaptive co-management. Journal of Sustainable Tourism 17:149-168. http://dx.doi.org/10.1080/096 $\underline{69580802359301}$

Pretty, J., and S. Vodouhe. 1997. Using rapid or participatory rural appraisal. Pages 47-55 in B. Swanson, R. Bentz, and A. Sofranko, editors. Improving agricultural extensions. Food and Agriculture Organization of the United Nations, Rome, Italy.

Reed, M., A. Dougill, and T. Baker. 2008. Participatory indicator development: what can 
ecologists and local communities learn from each other? Ecological Applications 18:1253-1269. http ://dx.doi.org/10.1890/07-0519.1

Reed, M., E. D. G. Fraser, S. Morse, and A. J. Dougill. 2005. Integrating methods for developing sustainability indicators to facilitate learning and action. Ecology and Society 10(1):r3. [online] URL: http://www.ecologyandsociety.org/vol10/iss1/resp3/

Ritchie, B., C. McDougall, and M. Haggith. 2000. Criteria and indicators of sustainability in community managed forest landscapes - an introductory guide. Center for International Forestry Research (CIFOR), Bogor, Indonesia.

Robinson, C., H. Ross, and M. Hockings. 2006. Development of co-management arrangements in the Great Barrier Reef: an adaptive management approach. CRC Reef, Technical Report 55, Townsville, Australia.

Ross, H., C. Grant, C. J. Robinson, A. Izurieta, D. Smyth, and P. Rist. 2009. Co-management and indigenous protected areas in Australia: achievements and ways forward. Australasian Journal of Environmental Management 16:242-252.

Ross, H., C. Robinson, and M. Hockings. 2004. Evaluation of Indigenous co-management of natural resources. Pages 51-58 in J. Bellany, editor. Regional natural resource management planning: the challenges of evaluation as seen through different lenses. CIRM Social Dimensions of NRM Working Group, Brisbane, Australia.

Ross, H., E. Young, and L. Liddle. 1994. 'Mabo: an inspiration for Australian land management'. Australian Journal of Environmental Management 1:24-41.

Sayer, J., B. Campbell, L. Petherman, M. Aldrich, M. Ruiz Perez, D. Endamana, A. Nzooh Dongmo, L. Defo, S. Mariki, N. Doggart, and N. Burgess. 2007. Assessing environment and development outcomes in conservation landscapes. Biodiversity Conservation:2677-2694. http://dx.doi.org/10.1007/ $\underline{\mathrm{s} 10531-006-9079-9}$

Setty, R. S., T. Bawa, T. Ticktin, and C. M. Gowda. 2008. Evaluation of a participatory resource monitoring system for nontimber forest products: the case of Amla (Phyllanthus spp.) fruit harvest by
Soligas in South India. Ecology and Society 13 (2):19. [online] URL: http://www.ecologyandsociety. org/vol13/iss2/art19/

Smyth, D. 2001. Joint management of national parks in Australia. Pages 75-91 in R. Baker, J. Davies, and E. Young, editors. Working on country: contemporary indigenous management of Australia's lands and coastal regions. Oxford University Press, Oxford, UK.

Swartling, A. G., and J. Forrester. 2010. Stakeholder participation and the work of SEI: an introduction. Pages 2-7 in J. Forrester, and A. G. Swartling, editors. Overcoming the challenges of 'doing participation' in environment and development: workshop summary of lessons learned and ways forward. Stockholm Environment Institute, Stockholm, Sweden.

Timko, J., and T. Satterfield. 2008. Seeking social equity in national parks: experiments with evaluation in Canada and South Africa. Conservation and Society 6:238-254. http://dx.doi. org/10.4103/0972-4923.49216

White, A. T., L. Z. Hale, Y. Renard, and L. Cortesi, editors. 1994. Collaborative and community-based management of coral reefs: lessons from experience. Kumarian Press Inc., Connecticut, USA.

Woodhill, J. 2000. Planning, monitoring and evaluation programmes and projects: introduction to key concepts, approaches and terms. The World Conservation Union (IUCN), Global Monitoring and Evaluation Initiative, Gland, Switzerland.

Zukoski, A. P., and M. Luluquisen. 2002. Participatory evaluation: promoting collective knowledge and action. What is it? Why do it? What are the challenges? Community Based Public Health Policy and Practice. 5:1-6. 